\title{
LEGUMINOSA NO CONTROLE INTEGRADO DE PLANTAS DANINHAS PARA AUMENTAR A PRODUTIVIDADE DA LARANJA-'PÊRA'1
}

\author{
JOSÉ EDUARDO B. DE CARVALHO²; LUCIANO DA S. SOUZA²; RANULFO C. CALDAS²; \\ PALLOMMA EMMANUELA U. T. ANTAS 3 ; ANA MARIA DE A. ARAÚJO ${ }^{3}$; LUCY C. LOPES ${ }^{4}$; \\ ROSANE C. DOS SANTOS ${ }^{3}$; NEIDE CONCEIÇÃO M. LOPES ${ }^{3}$; ANDRÉ LEONARDO V. SOUZA ${ }^{5}$
}

\begin{abstract}
RESUMO - Objetivou-se avaliar a produtividade da laranja-'Pêra', em dois ecossistemas, considerando dois diferentes manejos de solo para o controle integrado de plantas daninhas. O experimento foi instalado nos municípios de Rio Real e Conceição do Almeida, Bahia, no período de 1994 a 1999, em área total de $6000 \mathrm{~m}^{2}$, em cada local. O manejo utilizado pelo produtor constou de três capinas manuais nas linhas de plantio e três gradagens nas entrelinhas, enquanto o manejo proposto utilizou como cobertura vegetal o feijãode-porco (Canavalia ensiformes L.), nas entrelinhas do pomar, associado a uma subsolagem. O controle químico das plantas daninhas nas linhas do pomar foi realizado duas vezes ao ano com glifosate. O manejo proposto apresentou melhores resultados em relação ao manejo do produtor nos dois municípios para todos os parâmetros analisados: peso do fruto, número de frutos por planta e produtividade. Em Conceição do Almeida, o sistema proposto foi 56,8\% mais produtivo que o do produtor e, em Rio Real, 64,9\%.
\end{abstract}

Termos para indexação: Citros, manejo de solo, feijão-de-porco, controle de plantas daninhas.

\section{LEGUME PLANTS IN THE INTEGRATED WEEDS CONTROL TO IMPROVE ORANGE 'PERA' YIELD}

\begin{abstract}
Aimed to evaluate the productivity of sweet orange "Pera" grown considering two different ecosystems and under two soil management systems to control weeds. This work was carried out at the cities of Rio Real and Conceição de Almeida, Bahia State, during the period from 1994 to 1999. The soil management used by the farmer comprised three hoeings within planting lines and three harrowings between the planting lines. The new soil management proposed used a green cover of pig beans (Canavalia ensiformes, L.) between the planting lines along with subsoiling, associated with a chemical control of the weeds by Gliphosate, on the planting lines, twice a year. The soil management proposed yielded better results than the farmer soil management at both ecosystems for fruit weight of fruit, number, and plant productivity. At Conceição do Almeida and Rio Real the proposed soil management was 56,8\% and $64,9 \%$, respectively, superior than the farmer system.
\end{abstract}

Index terms: citrus, soil management, pig beans, weeds.

\section{INTRODUÇÃO}

A principal área citrícola da Bahia encontra-se na faixa litorânea, em solos de tabuleiros costeiros, nos quais predomina Latossolo Amarelo distrófico, coeso e de textura média, caracterizando-se pela baixa capacidade de retenção de água, baixos teores de argila e matéria orgânica, e pelo adensamento, que ocorre nos horizontes $\mathrm{AB}$ e $\mathrm{BA}$, atingindo em média de $15 \mathrm{a}$ $20 \mathrm{~cm}$ até 70 a $80 \mathrm{~cm}$ de profundidade. Esse adensamento tem um efeito negativo significativo ao restringir o aprofundamento do sistema radicular dos citros, concentrando-o quase que totalmente na camada de solo acima da coesa, penetrando muito pouco nesta, encontrando-se a maior parte das radicelas nos primeiros $30 \mathrm{~cm}$ do solo. Esses aspectos, associados à ocorrência de vários períodos de estiagem ao ano, em média cinco meses de poucas chuvas, tem acentuado a deficiência hídrica nas plantas, com prejuízo na produtividade da cultura.
Segundo Koffler (1986) citado por Mazza (1998) as altas produtividades alcançadas estão diretamente relacionadas as maiores profundidades exploradas pelos sistemas radiculares das plantas, em concordância com Oliveira (1991) que afirma haver estreita relação entre níveis de desenvolvimento do sistema radicular e a produtividade agrícola.

Face a alta porcentagem de areia no solo da região citrícola da Bahia, Cintra \& Coelho (1987) demonstraram que é indispensável, para a obtenção de produtividade adequada, a adoção de práticas culturais que permitam aumentar os teores de matéria orgânica e a capacidade de retenção de água dos solos. Por outro lado, a competição de plantas daninhas pelos fatores de produção, água, nutriente, luz e $\mathrm{CO}_{2}$ e seu manejo inadequado têm contribuído para as baixas produtividades observadas, principalmente para as condições de solos de "tabuleiros" costeiros, predominantes na citricultura nordestina.

Contudo, se as plantas cítricas necessitam de boa

1 (Trabalho 071/2001). Recebido: 27/03/2001. Aceito para publicação: 13/11/2001.

2 Pesquisador-Embrapa Mandioca e Fruticultura, Cruz das Almas, BA, Cx.P. 007, e-mail: jeduardo@cnpmf.embrapa.br, lsouza@cnpmf.embrapa.br, rcaldas@cnpmf.embrapa.br;

3 Bolsista-Embrapa Mandioca e Fruticultura, Cruz das Almas, BA

4 Pós - Graduanda da Escola de Agronomia da UFBA, Cruz das Almas,BA.

5 Bolsista-CNPq/PIBIC-Embrapa Mandioca e Fruticultura, Cruz das Almas, BA 
aeração e espaços vazios no solo para desenvolvimento do sistema radicular, o que garantirá um bom desenvolvimento da planta e alta produtividade, é possível otimizar o seu potencial genético, evitando-se também a degradação das propriedades físicas do solo. A resistência à penetração das raízes e a baixa aeração, acompanhada de insuficiente permeabilidade de água no solo e de uma camada de argila a $0,60 \mathrm{~m}$ de profundidade, foram os fatores que mais influenciaram o crescimento do sistema radicular da planta e, conseqüentemente, a produção dos citros (Nel \& Bennie,1984, citado por Demattê \& Vitti, 1992).

O manejo das plantas daninhas, adotado pelos produtores, tem ajudado a maximizar esses problemas, contribuindo para a baixa produtividade média observada na região (12t/ha/ano) e para a redução da longevidade da planta cítrica. Assim, a compactação nas entrelinhas da cultura, provocada pelo trânsito exagerado de máquinas, acarreta diminuição na macroporosidade, redução da disponibilidade de água no solo, dificultando o desenvolvimento do sistema radicular, o que reduz direta e indiretamente a absorção de nutrientes pelas plantas, mesmo com sua presença no solo. Outro aspecto negativo do manejo utilizado pelos citricultores é o corte freqüente das radicelas nas entrelinhas (Caetano, 1980), pois 50 a $60 \%$ delas estão nos primeiros $30 \mathrm{~cm}$ de profundidade (Moreira, 1983; Koudounas \& Papadreou, 1992), além de reduzir a macroporosidade e aumentar a densidade, diminuindo o desenvolvimento radicular e conseqüentemente a produção dos citros (Koga, 1972, citado por Demattê \& Vitti, 1992; Silva et al. , 1990).

Para que esses problemas possam ser minimizados, devem-se adotar medidas para melhorar as características físicas do solo de modo a permitir um desenvolvimento adequado do sistema radicular da cultura e, com isso, aumentar sua produtividade.

O trabalho teve como objetivo a avaliação da produtividade da laranja-'Pêra', com idade entre sete e nove anos, em dois ecossistemas diferentes, submetida a dois diferentes manejos de solo no controle integrado das plantas daninhas, levando em consideração as condições do solo trabalhado e as condições climáticas existentes.

\section{MATERIAL E MÉTODOS}

O experimento foi conduzido nos municípios de Rio Real e Conceição do Almeida, Estado da Bahia, no período de 1994 a 1999, em duas quadras, totalizando $6.000 \mathrm{~m}^{2}$, onde cada sistema ocupou $3.000 \mathrm{~m}^{2}$, com 128 plantas de laranja-'Pêra' (Citrus sinensis (L.) Osb.) sobre limão-'Cravo' (Citrus limonia (L.) Osb.). O tipo de solo do local trabalhado foi classificado como Latossolo Amarelo álico coeso. A Figura 1 apresenta a precipitação pluvial média dos anos estudados, nos dois ecossistemas diferentes.

Este experimento comparou o sistema de manejo utilizado pelo produtor, que constou de três capinas manuais nas linhas de plantio e três gradagens nas entrelinhas, com o sistema de manejo que utilizou como cobertura vegetal o feijãode-porco (Canavalia ensiformis L.) nas entrelinhas do pomar, associada à subsolagem, quando necessária. O controle químico das plantas daninhas, nas linhas da laranja 'Pêra', foi realizado em duas épocas do ano (março/abril e setembro/outubro), em função do período crítico de interferência dessas plantas com a cultura dos citros (Carvalho et al., 1993), utilizando-se de um herbicida pós-emergente à base de glifosate, na dose de $1 \% \mathrm{v} / \mathrm{v}$, aplicado com um pulverizador tratorizado.

Plantou-se a lanço o feijão-de-porco, nas entrelinhas dos citros, em 1994 e 95, e no sistema de plantio direto nos demais anos; a proporção utilizada foi de 80 a $100 \mathrm{~kg}$ de sementes por hectare. O plantio dessa leguminosa foi realizado no período das águas (maio/junho) e roçado no final (setembro/outubro), a uma altura média de $0,25 \mathrm{~m}$ do solo, e os restos foram deixados na superfície do solo para a formação a da palhada, evitando a competição por água nos períodos de deficiência hídrica no solo.

Nos dois municípios, a subsolagem foi realizada em maio de 95 , a uma profundidade média de $0,55 \mathrm{~m}$.

Nas quadras de Rio Real, foram colhidos os frutos de 56 plantas, nos anos de 1996 e 97, e de 39 plantas, no ano de 1995, enquanto, em Conceição do Almeida, foram colhidos os frutos de 48 plantas, nos anos agrícolas de 1996 a 99, para a avaliação da produção e posterior análise estatística.

Em 1998, não foi possível, em Conceição do Almeida, efetuar as duas colheitas que normalmente ocorrem por ano e, dessa maneira, optou-se por excluí-la da análise estatística: peso de fruto, número de frutos por planta e produtividade.

\section{RESULTADOS E DISCUSSÃO}

O manejo proposto foi significativamente melhor do que o adotado pelo produtor em quase todos os anos, única exceção feita em 1999, no município de Conceição do Almeida, cujas médias não diferiram estatisticamente entre os dois sistemas avaliados (Tabelas 1 e 2). Pode-se verificar, também, que o peso médio de fruto no sistema proposto $(145,6 \mathrm{~g})$ foi maior do que no sistema do produtor $(130,4 \mathrm{~g})$, no município de Rio Real, sendo o mesmo observado em Conceição do Almeida, onde o sistema proposto obteve uma média de $241,5 \mathrm{~g}$ e o sistema do produtor $234,5 \mathrm{~g}$, respectivamente. Trabalhos comprovam que o uso de cobertura morta na fruticultura protege o solo do impacto da chuva, aumenta a infiltração de água, incorpora matéria orgânica e melhora a estrutura do solo (Sanches, 1998), melhorando assim, as condições de crescimento do sistema radicular das plantas e, conseqüentemente, aumentando a produtividade, estando em concordância com os resultados obtidos nesse trabalho; com os de Koffler (1986), citado por Mazza (1998), onde altas produtividades alcançadas estão diretamente relacionadas às maiores profundidades exploradas pelos sistemas radiculares das plantas; e com Oliveira (1991), que afirma haver estreita relação entre níveis de desenvolvimento do sistema radicular e a produtividade agrícola.

Em Conceição do Almeida, o sistema proposto apresentou uma produtividade média, nos três anos de colheita (96,97 e 99), de 35,7 t/ha, enquanto o sistema do produtor obteve uma média de 22,9 t/ha; em Rio Real, a produtividade média do sistema proposto foi de $36,6 \mathrm{t} / \mathrm{ha}$, e do manejo do produtor foi de $22,2 \mathrm{t} / \mathrm{ha}$, proporcionando um aumento médio na produção de $37,6 \%$, para as duas áreas citrícolas em estudo (Figura 2). Atribuise o incremento de produtividade da laranja-'Pêra' à melhoria da estrutura do solo, proporcionada pelo manejo do feijão-de-porco 


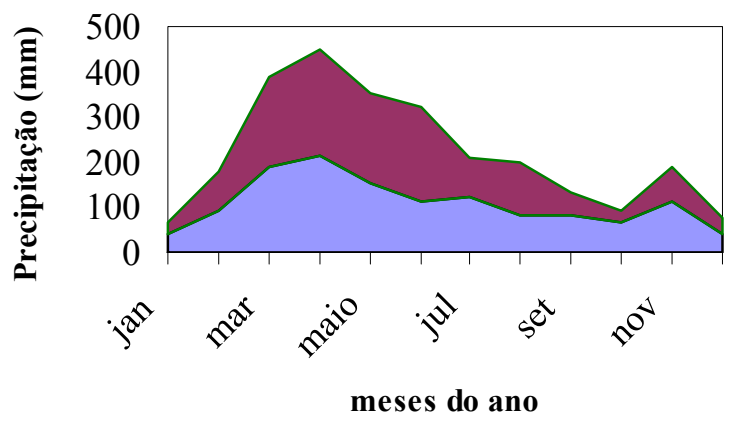

$\square$ C. do Almeida $\quad \square$ Rio Real

FIGURA 1 - Precipitação pluvial média mensal (mm) em Conceição do Almeida e Rio Real (BA), nos anos de 1996 e 1997.

TABELA 1 - Comparação entre dois manejos do solo, no município de Conceição de Almeida-BA, nos anos 1996, 1997 e 1999.

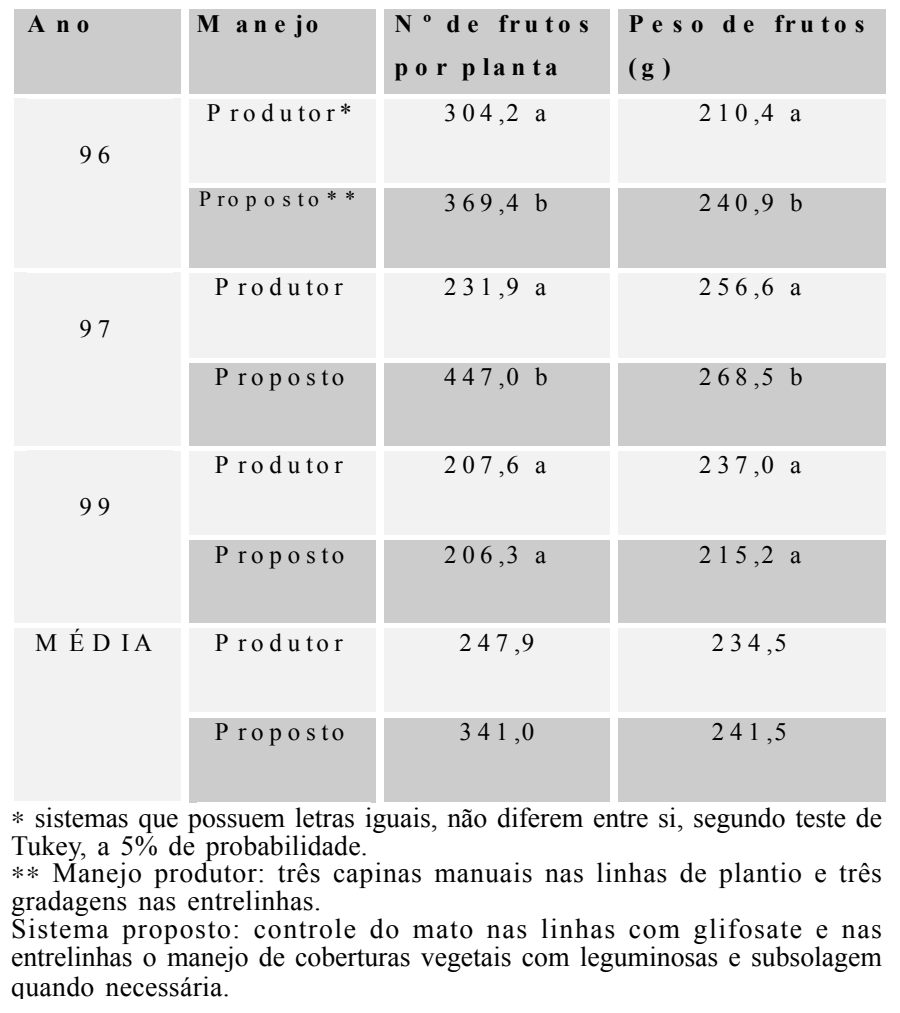

Colheitas Rio Real

Colheitas C. do Almeida

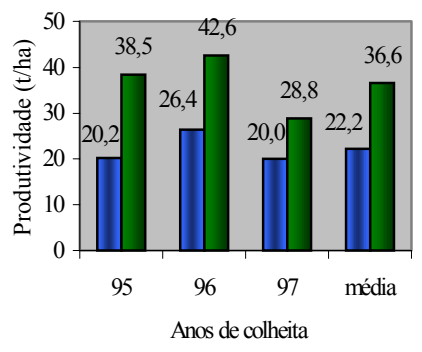

पprodutor $\square$ proposto

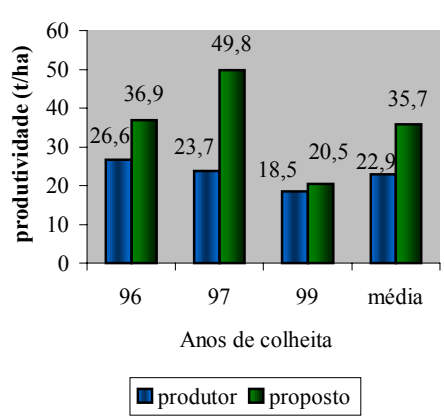

FIGURA 2 - Produtividade da laranja-'Pêra' (em t/ha) em dois sistemas diferenciados de manejo do solo, nos municípios de Rio Real (período de 95 a 97) e Conceição do Almeida (anos 1996, 1997 e 1999).
TABELA 2 - Comparação entre dois manejos do solo, no município de Rio Real-BA, nos anos 1995 a 1997.

\begin{tabular}{|c|c|c|c|}
\hline A no & M ane jo & $\begin{array}{c}N^{\circ} \text { de frutos } \\
\text { Por planta }\end{array}$ & $\begin{array}{c}\text { Peso de frutos } \\
(\mathrm{g})\end{array}$ \\
\hline \multirow{2}{*}{95} & Produtor* & $621,1 \mathrm{a}$ & 119,3 a \\
\hline & Proposto** & 640,3 a & $144,6 \mathrm{~b}$ \\
\hline \multirow{2}{*}{96} & Produtor & 506,8 a & 125,3 a \\
\hline & Propos to & $748,4 \mathrm{~b}$ & $136,6 \mathrm{~b}$ \\
\hline \multirow{2}{*}{97} & Produtor & 323,3 a & 147,9 a \\
\hline & Proposto & $446,1 \mathrm{~b}$ & $151,5 \mathrm{~b}$ \\
\hline \multirow[t]{2}{*}{ M É D I A } & Produtor & 487,7 & 130,4 \\
\hline & Proposto & 611,3 & 145,6 \\
\hline
\end{tabular}

- sistemas que possuem letras iguais, não diferem entre si, segundo teste de Tukey, a $5 \%$ de probabilidade.

* Manejo produtor: três capinas manuais nas linhas de plantio e três gradagens nas entrelinhas.

** Sistema proposto: controle do mato nas linhas com glifosate e nas entrelinhas o manejo de coberturas vegetais com leguminosas e subsolagem quando necessária.

associado a uma subsolagem na profundidade média de $0,55 \mathrm{~m}$, resultados esses sustentados pelos obtidos por Carvalho et al. (1998), que verificaram redução da densidade, aumento da macroporosidade e, conseqüentemente, da infiltração de água e por Carvalho et al. (1999) que concluíram que o manejo de coberturas vegetais em citros possibilitou um aumento e melhor distribuição do sistema radicular no perfil do solo, permitindo explorar maior volume de solo e garantindo, assim, mais disponibilidade de água e nutrientes para a laranja-'Pêra'. Os resultados desse trabalho estão coerentes com os obtidos por Mazza (1992), que verificou uma redução de 50\% na água armazenada e prontamente disponível num solo compactado e com os obtidos por Cintra \& Coelho (1987), onde demonstraram que, face à alta porcentagem de areia no solo da região citrícola da Bahia, é indispensável para a obtenção de produtividade adequada, a adoção de práticas culturais que permitam aumentar os teores de matéria orgânica e a capacidade de retenção de água dos solos.

\section{CONCLUSÃO}

O manejo proposto apresentou melhores resultados em relação ao manejo do produtor, nos dois locais estudados, para todas as variáveis avaliadas: peso de fruto, número de frutos por planta e produtividade. Em Conceição do Almeida, o sistema proposto foi $56,8 \%$ mais produtivo e, em Rio Real, 64,9\%, considerando-se apenas o item produtividade ( $\mathrm{t} / \mathrm{ha})$. 


\section{REFERÊNCIAS BIBLIOGRÁFICAS}

CAETANO, A. A. Tratos culturais. In: RODRIGUES, O. \& F. VIÉGAS, Coord. Citricultura Brasileira. Campinas, SP., 2: 42-466, 1980.

CARVALHO, J. E. B. de; SOUZA, L. da S.; JORGE, L. A. de C.; RAMOS, W. F.; NETO, A . de O . C.; ARAÚJO, A . M. de A .; LOPES, L. C.; JESUS, M. S. de. Manejo de coberturas do solo e sua interferência no desenvolvimento do sistema radicular da laranja-'Pêra'. Revista Brasileira de Fruticultura, Cruz das Almas, BA, v.21, n.2, p. 140-145, 1999.

CARVALHO, J. E. B. de; SOUZA, L. da S.; SOUZA, L. D.; RAMOS, W. F. et al. Manejo do solo no controle integrado de plantas daninhas em citros. Revista Brasileira de Fruticultura, Cruz das Almas, BA, v. 20, n.1, p. 21-27, 1998.

CARVALHO, J. E. B. de; CARDOSO, S. da S.; COSTA NETO, A. de O. Influência das épocas de controle das plantas daninhas sobre a produção de laranja-'Pêra'. Planta Daninha, Brasília, DF, v. 11, n.1-2, p. 49-54, 1993.

CINTRA, F. L. D., COELHO, Y. da S. Caracterização física do solo em pomares da região do Recôncavo baiano. Revista Brasileira de Fruticultura, Cruz das Almas, BA, v. 9, n. 1 p. 27-35, 1987.

DEMATTÊ, J. L. I.; VITTI, G. C. Alguns aspectos relacionados ao manejo de solos para os citros. In: SEMINÁRIO INTERNACIONAL DE CITROS-FISIOLOGIA, 2., 1992, Bebedouro, SP. Anais... Campinas, SP: Fundação Cargill, 1992. p.67-99.

KOUDOUNAS, C.; PAPADREOU, T. Soil-citrus relationship studies in Cyprus. Acta Horticultural, The Hague, n.365, p. 147150,1994 . International Symposium on Current Development in Mediterrane na Tropical and Subtropical Fruit Production and Research, Nicosia, Cyprus, 1992.

MAZZA, J.A. Importância das características físico-hídricas. In: SEMINÁRIO INTERNACIONAL DE CITROS-TRATOS CULTURAIS, 5., 1998, Bebedouro, SP. Anais... Campinas, SP: Fundação Cargill, p.189-202.

MAZZA, J. A. Avaliação de compactação e sistema radicular de citros nas Fazendas Nova Prata e Samambaia, Colina/SP. Piracicaba, 15p. 1992. (Relatório Técnico).

MOREIRA, C. S. Estudo da distribuição do sistema radicular da laranjeira-'Pera' Citrus sinensis (L.) Osbeck, com diferentes manejos de solo. 1983, 97 f. Tese (Livre Docência) - Escola Superior de Agricultura Luiz de Queiroz, Universidade de São Paulo, Piracicaba.

OLIVEIRA, J. B.. Solos para citros. In: RODRIGUEZ, O., VIÉGAS, F., POMPEU JR., J. \& AMARO, A. A., eds. Citricultura Brasileira. Campinas, Fundação Cargill, v.1, p. 196-227. 1991.

SANCHES, A. C. Conservação do solo em pomares cítricos. In: SEMINÁRIO INTERNACIONAL DE CITROS-TRATOS CULTURAIS, 5., 1998, Bebedouro, SP. Anais... Campinas, SP: Fundação Cargill, p.167-187.

SILVA, A. D.; FOLEGATTI, M.; TORRADO, P. Avaliação dos efeitos da subsolagem em parâmetros físicos do solo em pomares de laranja. Piracicaba, SP: Escola Superior de Agricultura Luiz de Queiroz, 28p. 1990. (Relatório do Departamento de Solos). 